\title{
Maternal and foetal risk factors of cerebral palsy among Iraqi children: A case control study
}

\author{
Hussain R. Saadi ${ }^{*}$, Rosnah Sutan ${ }^{1}$, Aqil M. Dhaher ${ }^{2}$, Serene A. Alshaham ${ }^{3}$ \\ ${ }^{1}$ Department of Community Health, University Kebangsaan Malaysia Medical Centre, Kuala Lumpur, Malaysia; \\ ${ }^{*}$ Corresponding Author: albayatihussain@yahoo.com \\ ${ }^{2}$ Departments of Preventive Medicine, Official Portal of Universiti Teknologi MARA, Kuala Lumpur, Malaysia \\ ${ }^{3}$ Department of Family Medicine, University of Mississippi Medical Center, Kuala Lumpur, Malaysia
}

Received 1 March 2012; revised 16 April 2012; accepted 2 May 2012

\section{ABSTRACT}

Background: The importance of studying cerebral palsy comes from the fact that, this disorder imposes huge burden families psychologically, emotionally, financially and socially. Moreover, it imposes a major burden on the National Health System because it is simply a chronic disorder, which needs a continuous care and multiple financial resources. At the same time, it needs collaborative efforts and team work between many parties and organizations for a good management and rehabilitation. In Iraq, risk factors of cerebral palsy have not been explored before. Our study objective was to measure the association between, maternal factors, foetal and early neonatal factors, and occurrence of cerebral palsy among Iraqi children. Postnatal risk factors of cerebral palsy were excluded in our study. Methods: We did a retrospective casecontrol study in Baghdad-Iraq. The place of study was The Central hospital of Children of Baghdad. Cases and controls were fully investigated (retrospectively) for the risk factors of cerebral palsy using a self-administered questionnaire. The sample size was 300 . Number of cases in our study was 100 while the number of controls in our study was 200. Results and Conclusion: $84 \%$ of the mothers of Cerebral Palsy children were employed compared to $49 \%$ of the mothers of normal children who were employed ( $P$ value 0.00). After using a multiple logistic regression model, the final adjusted odd ratios included 6 variables which were, employment of mother (OR 8.05, 95\% CI 0.98 - 6.62), Primigravida (OR $0.24,95 \% \mathrm{Cl} 0.10-0.60$ ), gender of the child (OR $0.15,95 \% \mathrm{Cl} 0.04-0.51$ ), asphyxia (OR 10.58, $95 \%$ Cl 3.59 - 31.21), hypoglycemia (OR 40.99, $95 \% \mathrm{Cl} 6.93-242.27$ ) and hypocalcaemia (OR
$27.91,95 \% \mathrm{Cl} 2.04$ - 380.96). Our study came to a conclusion that neonatal asphyxia, hypoglycemia and hypocalcaemia were still the major risk factors for cerebral palsy In Iraq.

Keywords: Cerebral Palsy; Risk Factors; Maternal; Foetal; Iraq; Case-Control

\section{INTRODUCTION}

Cerebral palsy (CP) is a symptom complex, rather than a specific disease. The most recent consensus definition states that cerebral palsy is an "umbrella term covering a group of non-progressive, but often changing, motor impairment syndromes secondary to lesions or anomalies of the brain arising in the early stages of its development". Cerebral palsy is one of the most chronic conditions which may lead to disability in childhood. The prevalence of cerebral palsy is $1.2-2.5$ per 1000 live births although, the rates vary from country to country and also within the countries [1].

Cerebral palsy refers not to a single condition but to a number of different and varied chronic conditions. The traditional definition of cerebral palsy is a non-progressive impairment in movement or posture caused by injury or anomaly of the developing brain [2].

It is the most common neuro motor developmental disability of childhood, affecting as many as 8000 to 12,000 children born in the USA each year, corresponding to a prevalence rate of between 2 and 3 per 1000 children [3].

Recent improvements in neonatal care have not resulted in a decline in the overall prevalence of cerebral palsy and, in fact, greater numbers of very preterm, very low birth weight infants are surviving with cerebral palsy and other developmental problems.

Cerebral palsy is a condition which occurs due to antenatal, neonatal or postnatal causes. Therefore, the emphasis would mainly be on the availability of a functional 
and efficient antenatal care and on the availability of a well-equipped neonatal care units and services to avoid the problem of having babies with cerebral palsy. We were aiming that; this study would highlight the need for more emphasis on antenatal and neonatal care services in Iraq. We also hoped that, this study could detect the real association between the hypothesized risk factors and the occurrence of cerebral palsy among mothers of CP and $\mathrm{CP}$ children born in Baghdad. Last but not least, we thought that, this study would give an explanation for the increasing incidence and prevalence of cerebral palsy among Iraqi children.

In Iraq, neonatal care services are facing a challenging situation especially in the rural and remote areas in the south of the country. These factors have all contributed to the increased percentage of children born with many health disorders in Iraq. However, shortages in studies exploring the actual numbers and prevalence of these health problems have not helped those under privileged population get the proper attention they need. Cerebral palsy was one of those disorders which witnessed an increasing trend of incidence after 1990 in Iraq. Those disorders which were classified as chronic disorders did not get the full sponsorship of the government at that time as the priority in health care services was shifted towards more acute health problems. At the same time, the national income was also shifted towards military spending in favorite of spending on other sectors of community like health and education. Exact numbers of the magnitude of cerebral palsy problem in Iraq is not available, so hopefully, this study would help give some highlights on the problem of Cerebral palsy in Iraq.

\subsection{Maternal and Obstetric Risk Factors of CP}

Maternal and obstetric factors have been discussed in many studies before as potential risk factors for CP. In Iraq however, we don't have any study before about any possible correlation between maternal, obstetric or foetal risk factors with occurrence of $\mathrm{CP}$. The antenatal period extends from conception to the time of birth. Disabling problems can occur at any point in the developmental process between those two events [2].

These maternal risk factors and their correlation with occurrence of CP have been highlighted in few studies around the world. In one study, a researcher has found that, of the $6,145,357$ deliveries examined during the study 8946 cases of CP were identified ( 1.45 per 1000 live births). In both $\mathrm{CP}$ groups, there were significantly increased risks of $\mathrm{CP}$ related to advanced maternal age ( $>40$ y) and increasing parity; Pregnancy risk factors (e.g. chronic hypertension and preeclampsia). Gestational (but not pre gestational) diabetes increased the risk in term babies by $19 \%$ vs. controls. Maternal infection was seen more frequently in term cases of CP. Intra partum adverse events likely to be associated with CP (all of which have been documented in past studies) were: foetal distress $(19.7 \%$ in all $\mathrm{CP}$ cases, vs. $7.7 \%$ in controls, $\mathrm{P}<$ $0.0001)$; birth trauma $(7.8 \%$, vs. $4.8 \%$ in controls, $\mathrm{P}<$ $0.0001)$; placental abruption $(5.7 \%$, vs. $0.9 \%$ in controls, $\mathrm{P}<0.0001)$; mild-severe birth asphyxia $(5.7 \%$, vs. $0.4 \%$ in controls, $\mathrm{P}<0.0001)$; cord prolapse $(1.5 \%$, vs. $0.3 \%$ in controls, $\mathrm{P}<0.0001)$; and uterine rupture during labor $(0.8 \%$, vs. $0.06 \%$ in controls, $\mathrm{P}<0.0001)$. Overall, children with $\mathrm{CP}$ had a significantly greater rate of one or more of these events than controls $(31.3 \%$, vs. $12.9 \%$, P $<0.0001)$ [4].

In 1993, one researcher added on a hypothesis put forth by Adinolfi that, maternal infection during pregnancy might lead to neurologic impairment and the development of $\mathrm{CP}$ via cytokines by suggesting that cytokines contribute not only to neurologic impairment, but to preterm birth as well. This prenatal hypothesis regarding the etiology of $\mathrm{CP}$ has later on come to be known as the inflammatory/cytokine hypothesis [5].

Infection/inflammation might appear in the form of intrauterine infection (chorioamnionitis) as well as extra uterine infection, that is, pyelonephritis and other forms of maternal infection. Chorioamnionitis, either clinical or subclinical, is a well-known risk factor for CP [6].

Another researcher has recently been studying the correlation between chorioamnionitis and cerebral palsy in a Meta-analysis study. Twelve of the 15 studies had data on the association between clinical chorioamnionitis and cerebral palsy with an OR that ranged from 0.9 to 5.8 [7].

Multiple gestations encompass several antenatal complications including preterm labor, death of a co-twin, growth restriction, and birth defects of one or more fetuses. All of these events or occurrences can be associated with $\mathrm{CP}$. In addition, twins are known to be at a higher risk of developing $\mathrm{CP}$ than singleton gestation $[8,9]$.

In one study, and using the Western Australia CP Register from 1980 to 1989 to investigate the rates of CP in twins and triplets. They mentioned that, twins were at higher risk for developing CP than singletons, with the risk of a child having $\mathrm{CP}$ being $0.2 \%, 1.3 \%$, and $7.6 \%$ for singleton, twin, and triplet pregnancies, respectively [10].

Using the Scottish Register and Scottish Morbidity Record for 1984 to 1990 to look for etiologic factors and patterns of CP in multiples and singletons, one team of researchers found that of the 646 children with $\mathrm{CP}$ included in the study for analysis, twins were 4.8 times more likely to develop CP. The CP prevalence per 1000 neonatal survivors for singletons was 1.32 (95\% confi- 
dence interval: 1.22 - 1.44) and for twins it was 6.39 (95\% confidence interval: 4.97 - 8.22) [11].

\subsection{Foetal and Neonatal Risk Factors of CP}

The perinatal period is the time immediately before and after birth. Disabilities originating from this time period are primarily biomedical ones. They may result from many causes like, drugs taken during labour and delivery, prematurity, injury, oxygen deprivation, or infections acquired during the way through the birth canal.

There was one very interesting study, which was trying to determine the neonatal predictors of cerebral palsy in extremely low birth weight infants $(<1000 \mathrm{~g})$. The outcome variables for this study included maternal demographics, obstetric complications, and neonatal outcomes like (gestational age at delivery, birth weight, Apgar scores, intrauterine growth restriction, respiratory distress syndrome, intraventricular hemorrhage and neonatal sepsis). Interestingly, the results of this study showed that, primigravid (OR $=5.52,95 \%$ CI $1.67-18.3)$, early neonatal sepsis $(\mathrm{OR}=12.9,95 \% \mathrm{CI} 2.94-57.2)$ and chorioamniomtis $(\mathrm{OR}=3.71,95 \%$ CI $1.16-11.9)$ all were significantly associated with the development of cerebral palsy. As in any other disease or syndrome, CP risk factors do interact with each other's and do correlate to each other's [12].

It has been well established that both the preterm infant and low birth weight infant are at particular risk for $\mathrm{CP}$. The etiology of a large portion of preterm births, particularly in the very preterm infant, is believed to be intrauterine infection. It is known that microorganisms from the lower genital tract can gain access to the intrauterine cavity and subsequently infect the placenta, membranes, and fetus. Recent studies suggest that feto-placental and uterine infection/inflammation play a role in the initiation of preterm labor and contribute to the development of central nervous system injury and CP [13].

Neonatal asphyxia has also been a known risk factor for developing CP. It may occur during a prolonged or difficult birth, and, because the brain suffers damage very quickly without a fresh and adequate supply of oxygen, brain damage can result. One major danger associated with birth is haemorrhage, which is caused when very strong pressure on the head of the foetus breaks blood vessels in the brain. Another danger is failure of the infant to begin breathing soon after being separated from the maternal source of oxygen [14].

Asphyxia in a new-born is more likely to damage the cells of the brain stem than those of the cortex, and to result in motor defects. The child may experience paralysis of the legs or arms, a tremor of the face or fingers, or inability to use the vocal muscles. In this last case, the child may have difficulty learning to speak. The term cerebral palsy describes a variety of motor defects asso- ciated with damage to the brain cells, possibly as a result of lack of oxygen during birth process. It is estimated that about $30 \%$ of cerebral palsy cases involve problems that occurred during birth or immediately afterward [15].

For decades, birth asphyxia was believed to be the predominant etiology of CP. More recently, multiple antenatal factors have been shown to be likely causes of $\mathrm{CP}$ in both the preterm and term infant, with birth asphyxia playing a minor role.

It is now believed that $70 \%$ to $80 \%$ of cases of $\mathrm{CP}$ are due to antenatal 1 factors with $10 \%$ to $28 \%$ of CP cases due to birth asphyxia in term and near-term infants as one study suggested that birth asphyxia may not be such an important cause of $\mathrm{CP}$ but might constitute one element of a multifactorial cause, that neonatal signs associated with birth asphyxia might be early manifestations of $\mathrm{CP}$ from a variety of causes, of which birth asphyxia is only one [16].

\section{METHODS AND MATERIALS}

In this study the total number of participants was 300 . A hundred cases and 200 controls. Sample size was calculated by Epi info program. This study was carried out in Iraq-Baghdad, the capital and the highest populated city in Iraq (nearly 7 million populations) for the period from March 2011 to October 2011. Baghdad is a multiethnic, multinational and multi-religious city. For that reason, generalization of the result to all of Iraq will be acceptable later on. One more reason of choosing Baghdad city as the study location is that, the Central Hospital of Children in Baghdad is considered as the main hospital which, most of the cases of cerebral palsy in Iraq are referred to, which makes collecting the sample for the study a bit easier process.

We chose a retrospective case-control study design as it was the most possible design to conduct that can assess the correlation between our dependent and independent variables. Moreover, both cross sectional and cohort studies were very difficult to conduct in Baghdad due to the insecurity situation there and the difficulty in accessing many health centers. The sample population for the case-control study was children (older than 2) who were born in Baghdad.

We chose a retrospective case-control study design as it was the most possible design to conduct that can assess the correlation between our dependent and independent variables. Moreover, both cross sectional and cohort studies were very difficult to conduct in Baghdad due to the insecurity situation there and the difficulty in accessing many health centers. The sample population for the case-control study was children (older than 2) who were born in Baghdad.

Cases were $\mathrm{CP}$ children (older than 2 years) who were already diagnosed and confirmed by a consultant pedia- 
trician or neurologist or both. The diagnoses depend on the nature of the signs and symptoms, the criteria of the disorder, history, clinical signs and symptoms as well as scanning imaging of the brain. Choosing children older than 2 was because a child with CP cannot be reliably diagnosed before completing 2 full years of age, due to the overlapping of the specific diagnostic features of cerebral palsy in this age group with diagnostic features of other similar neurological or behavioral conditions.. Cases of cerebral palsy were collected from the central hospital of children in Baghdad (which is supposed to receive all new cases of cerebral palsy to confirm the diagnoses and to follow up treatment and rehabilitation, whether inside or outside the hospital. The inclusion criteria for the cases were; alive child, older than 2 , born in Iraq, Children born and cared by their biological mothers, all are children diagnosed and confirmed with CP by a pediatrician or neurologist or both, and finally those cases should be accessing the hospital during the sample collection period. Exclusion criteria included: Children who were not born at hospitals or medical centers or those who have no medical records, Children with a history of one or more of those postnatal risk factors of CP which were excluded from the study like: Cerebral infarction, Neonatal sepsis, Hyperbilirubinemia, Sepsis, toxemia, encephalitis, Meningitis (CNS infections), intraventricular hemorrhage, periventricular leukomalacia, shaken baby syndrome and head injury.

Controls of our study were children who were chosen from a list of community based children who were collected from different nursery cares, kindergartens and schools. Inclusion criteria for the controls were: with the same age of the cases and, who do not have any signs or symptoms of cerebral palsy.

Sampling method for cases was universal sampling by choosing all the available cerebral palsy children older than 2 years, who, we could have a contact with their parents in the Central Children hospital during the period of the study (March-October 2011). We managed to get 123 cases but only 100 of them agreed to participate in the study. For controls, the sampling method was a systematic sampling by choosing every $5^{\text {th }}$ child from a list of 1000 normal children. We managed to get 200 controls to take part in our study. Cases and controls were matched by age and sex at the very early stages of the study.

Then the cases and the controls were fully investigated (retrospectively) for the risk factors of cerebral palsy using a questionnaire including demographic criteria, maternal risk factors and foetal risk factors.

A pre-test of the questionnaire was done for 30 mothers of CP children to ensure that, the questions were easily understood. The researcher has changed the questionnaire on 3 attempts to improve the phrasing of the questions and make it much more understandable to the local participants. The pre-test was done individually by the researcher. Approval for this study was obtained from the ethical committee of PPUKM FF-301-2011 on 29 July 2011. Data analyses were done using "Statistical Package for Sciences" (SPSS) Version 15. Descriptive Statistics data of the mean, standard deviation were obtained. Risk analyses between the 2 groups were obtained, Pearson qi-square. Then finally univariate and multivariate analyses were both applied to determine the relationship between the significant risk factors of cerebral palsy. Crude and adjusted Odd ratios were calculated.

\section{RESULTS}

Table 1 shows the mean and standard deviation of 3 selected descriptive variables for cases and controls. The mean age of the mothers of normal children enrolled in this study was 24.6 years while the mean age of the mothers of CP children was 26 years. Mean age of the normal child who took part in the study was 5 while the mean age of the child affected with $\mathrm{CP}$ was 5.4 years. Mean income of a family of normal and CP children did not show huge difference (613.10, 739.50 respectively). It is important to mention that, the data of those 3 variables mentioned in Table 2 were normally distributed.

In the descriptive analyses (Table 2), and in terms of race, $95.3 \%$ of the mothers of $\mathrm{CP}$ children enrolled in the study were Arabic, 3\% were Turkmen and only 1.7\% was Kurds. $94.4 \%$ of the mothers were married, $4.3 \%$ were widowed and $1.3 \%$ of them were divorced. Only $16 \%$ of all mothers of CP children were consanguineous married. Moreover, $61 \%$ of all 300 mothers involved in the study were employed and last, $16 \%$ of all mothers were illiterate.

After that we did a bivariate analyses for all sociodemographic, maternal, obstetric and foetal variables among cases and controls and then we took all the significant variables (which showed $\mathrm{P}$ value $\leq 0.05$ ) to the univariate model.

In Table $\mathbf{3}$ which is a bivariate analysis of Sociodemographic variables according to $\mathrm{CP}$ group. We can see that $84 \%$ of the mothers of Cerebral Palsy children were employed compared to $49 \%$ of the mothers of normal children who were employed ( $P$ value 0.00$)$.

In Table 4 which is a bivariate analysis of maternal

Table 1. Mean and standard deviation of selected variables.

\begin{tabular}{ccc}
\hline Variables & $\begin{array}{c}\text { CP Child } \\
\text { Mean } \pm \text { SD }\end{array}$ & $\begin{array}{c}\text { Normal Child } \\
\text { Mean } \pm \text { SD }\end{array}$ \\
\hline Mother's age at delivery & $26.08 \pm 4.99$ & $24.64 \pm 4.40$ \\
Child age now & $5.41 \pm 1.39$ & $5.08 \pm 1.32$ \\
Income of family (US\$) & $739.5 \pm 335.5$ & $613.1 \pm 296.6$ \\
\hline
\end{tabular}


Table 2. Descriptive statistics.

\begin{tabular}{cc}
\hline \multicolumn{1}{c}{ Variables } & $\%$ \\
\hline Race & 95.3 \\
Arabic & 1.7 \\
Kurdish & 3 \\
Turkmen & \\
Marital status & 94.4 \\
Married & 1.3 \\
Divorced & 4.3 \\
Widow & \\
Consanguineous marriage & 84 \\
No & 16 \\
Yes & \\
Employment of mother & 39 \\
No & 61 \\
Yes & \\
Education & 16 \\
Illiterate & 45 \\
Primary & 30 \\
Secondary & \\
Graduate level & \\
\hline
\end{tabular}

Table 3. Comparison of sociodemographic variables for mothers of cases and controls.

\begin{tabular}{lccc}
\hline \multicolumn{1}{c}{ Variables } & $\begin{array}{c}\text { CP child } \\
(\mathrm{n}=100) \%\end{array}$ & $\begin{array}{c}\text { Normal child } \\
(\mathrm{n}=200) \%\end{array}$ & P value \\
\hline $\begin{array}{l}\text { Employment of } \\
\text { Mother }\end{array}$ & & & 0.00 \\
$\quad$ No & 16 & 51 & \\
Yes & 84 & 49 & 0.81 \\
Race & & & \\
Arabic & 96 & 95 & \\
Kurds & 1 & 2 & 0.00 \\
Turkmen & 3 & 3 & \\
Education & & & \\
Illiterate & 16 & 15.5 & \\
Primary & 29 & 53.5 & \\
Secondary & 48 & 21.5 & \\
Graduate & 7 & 9.5 & \\
Consanguineous & & 89.5 & \\
Marriage & & 10.5 & \\
No & 72 & & \\
Yes & 28 & & \\
\hline
\end{tabular}

Table 4. Comparison of selected maternal and obstetric variables for mothers of cases and controls.

\begin{tabular}{|c|c|c|c|}
\hline Variables & $\begin{array}{c}\text { CP child } \\
(\mathrm{n}=100) \%\end{array}$ & $\begin{array}{l}\text { Normal child } \\
(\mathrm{n}=200) \%\end{array}$ & $\mathrm{P}$ value \\
\hline $\begin{array}{l}\text { Smoking during } \\
\text { pregnancy }\end{array}$ & & & 0.22 \\
\hline No & 92 & 95.5 & \\
\hline Yes & 8 & 4.5 & \\
\hline $\begin{array}{l}\text { Number of } \\
\text { pregnancies }\end{array}$ & & & 0.00 \\
\hline Primigravida & 67 & 46.5 & \\
\hline Multigravida & 33 & 53.5 & \\
\hline Intrauterine infection & & & 0.46 \\
\hline No & 90 & 92.5 & \\
\hline Yes & 10 & 7.5 & \\
\hline Chorioamnionitis & & & 0.00 \\
\hline No & 75 & 91 & \\
\hline Yes & 25 & 9 & \\
\hline $\begin{array}{l}\text { HT (Hypertension) } \\
\text { during pregnancy }\end{array}$ & & & 0.15 \\
\hline No & 94.9 & 94 & \\
\hline Yes & 5.1 & 6 & \\
\hline DM (Diabetes) & & & 0.07 \\
\hline No & 94 & 98 & \\
\hline Yes & 6 & 2 & \\
\hline $\begin{array}{l}\text { Abnormal position } \\
\text { of fetus }\end{array}$ & & & 0.47 \\
\hline No & 96 & 97.5 & \\
\hline Yes & 4 & 2.5 & \\
\hline $\begin{array}{l}\text { Premature rupture } \\
\text { of membrane }\end{array}$ & & & 0.26 \\
\hline No & 97 & 96 & \\
\hline Yes & 3 & 4 & \\
\hline
\end{tabular}

variables according to $\mathrm{CP}$ group, only the number of pregnancies variable showed significance (P value 0.00 ).

Also in Table 4 we can clearly see that, smoking during pregnancy was not a significant variable, as there was very small numbers of smoking mothers of both cases and control children.

Another significant comparison was for the chorioamnionitis, which showed a $\mathrm{P}$ value of 0.00 as $25 \%$ of mothers of all cases had chorioamnionitis compared to only $9 \%$ of mothers of all controls who had chorioamnionitis (Table 5).

In Table 6, we compared the foetal and neonatal variables among cases and controls. The gender of the child 
Table 5. Comparison of selected foetal and early neonatal variables for cases and controls.

\begin{tabular}{lccc}
\hline \multicolumn{1}{c}{ Variables } & $\begin{array}{c}\text { CP child } \\
(\mathrm{n}=100) \%\end{array}$ & $\begin{array}{c}\text { Normal child } \\
(\mathrm{n}=200) \%\end{array}$ & P value \\
\hline Gender of child & & & 0.00 \\
Male & 92 & 71.5 & \\
female & 8 & 28.5 & 0.08 \\
Apgar score & & & \\
More than 8 & 96 & 99 & 0.00 \\
Less than 8 & 4 & 1 & \\
Asphyxia & & & \\
No & 76 & 96 & 0.00 \\
Yes & 24 & 4 & \\
Hypoglycemia & & & \\
No & 88 & 99 & 0.01 \\
Yes & 12 & 1 & \\
Hypocalcaemia & & & \\
No & 95 & 99.5 & \\
Yes & 5 & 0.5 & \\
Respiratory distress & & & \\
No & & & \\
Yes & & & \\
\hline
\end{tabular}

showed a significant difference as percentage of male children among cases was $92 \%$ while the percentage of male children among controls was $71.5 \%$ (P value 0.000 ). percentage of children who had asphyxia among cases was $24 \%$. Whereas percentage of children who had asphyxia among controls was only $4 \%$ (P value 0.000 ).

In Table 7, we tested how much we can predict of Cerebral Palsy by each independent variable without looking at the overall effect of all variables together (Crude Odd ratio).

The variables with highest crude odd ratios in this model were, hypoglycemia (OR 13.5 P value 0.001), hypocalcaemia (OR 10.5, P value 0.03 ), and asphyxia (OR 7.6, P value 0.00) respectively. However, in this univariate model we did not take the effects of all variables on each other's. This may initiate confounders to interfere. Then we took all the significant variables (P value $\leq 0.05)$ to the more sophisticated multiple regression model.

In the multiple regression model we mixed all the independently significant variables with each other's to predict the effects of each other's and to come up with the more adjusted odd ratios for the significant variables and to control for the confounders that may initiate in early analyses stages (Table 7).
Table 6. Crude odd ratios.

\begin{tabular}{|c|c|c|c|c|}
\hline \multirow{2}{*}{ Variables } & \multicolumn{4}{|c|}{$(95 \% \mathrm{CI})$} \\
\hline & $P$ value & Odd ratio & Lower & Upper \\
\hline Age of mother & 0.01 & 1.06 & 1.01 & 1.12 \\
\hline Income (US\$) & 0.00 & 1.00 & 1.00 & 1.00 \\
\hline \multicolumn{5}{|l|}{ Race } \\
\hline Arabic & 0.53 & 0.45 & 0.05 & 4.48 \\
\hline Kurds & 0.98 & 0.99 & 0.24 & 4.04 \\
\hline Employment & 0.00 & 5.46 & 2.99 & 9.98 \\
\hline \multicolumn{5}{|l|}{ Education } \\
\hline Illiterate & 0.53 & 1.40 & 0.49 & 4.02 \\
\hline Primary & 0.53 & 0.73 & 0.28 & 1.92 \\
\hline Secondary & 0.02 & 3.03 & 1.16 & 7.91 \\
\hline $\begin{array}{l}\text { Smoking during } \\
\text { pregnancy }\end{array}$ & 0.22 & 1.84 & 0.69 & 4.94 \\
\hline \multicolumn{5}{|l|}{$\begin{array}{l}\text { Number of } \\
\text { pregnancies }\end{array}$} \\
\hline Primigravida & 0.00 & 0.25 & 0.13 & 0.50 \\
\hline Multigravida & 0.37 & 0.75 & 0.40 & 1.41 \\
\hline Aid from NGO & 0.22 & 3.06 & 0.50 & 18.63 \\
\hline Twins pregnancy & 0.53 & 0.65 & 0.17 & 2.48 \\
\hline $\begin{array}{l}\text { Intrauterine } \\
\text { infection }\end{array}$ & 0.46 & 1.37 & 0.59 & 3.17 \\
\hline Chorioamnionitis & 0.00 & 3.37 & 1.74 & 6.54 \\
\hline $\begin{array}{l}\text { Premature rupture } \\
\text { of membrane }\end{array}$ & 0.27 & 1.80 & 0.63 & 5.13 \\
\hline $\begin{array}{l}\text { Separation of part or } \\
\text { all of placenta }\end{array}$ & 0.48 & 0.56 & 0.11 & 2.76 \\
\hline Assisted delivery & 0.18 & 1.48 & 0.82 & 2.67 \\
\hline Gender of child & 0.00 & 0.21 & 0.10 & 0.47 \\
\hline Baby birth weight & 0.22 & 0.46 & 0.13 & 1.57 \\
\hline Asphyxia & 0.00 & 7.58 & 3.26 & 17.61 \\
\hline Hypoglycemia & 0.00 & 13.50 & 2.95 & 61.59 \\
\hline Hypocalcaemia & 0.03 & 10.47 & 1.21 & 90.90 \\
\hline Respiratory distress & 0.45 & 1.32 & 0.64 & 2.70 \\
\hline $\begin{array}{c}\text { Access to antenatal } \\
\text { care }\end{array}$ & 0.18 & 1.81 & 0.75 & 4.36 \\
\hline
\end{tabular}

The final multiple logistic regression model in Table 7, included 6 variables (Adjusted Odd ratio). Employment was the first independently significant variable with $\mathrm{P}$ value 0.000 and OR 8.05 (CI 3.6 - 17.9). Gender of the child was also independently significant $(\mathrm{P}$ value $\leq 0.05$, 
Table 7. The final adjusted odd ratios.

\begin{tabular}{ccccc}
\hline \multirow{2}{*}{ Variables } & \multicolumn{4}{c}{$(95 \% \mathrm{CI})$} \\
\cline { 2 - 5 } & P value & Odd ratio & Lower & Upper \\
\hline Employment of mother & 0.00 & 8.05 & 3.61 & 17.95 \\
Primigravida & 0.00 & 0.24 & 0.10 & 0.60 \\
Gender of child & 0.00 & 0.15 & 0.04 & 0.51 \\
Asphyxia & 0.00 & 10.58 & 3.59 & 31.21 \\
Hypoglycemia & 0.00 & 40.99 & 6.93 & 242.27 \\
Hypocalcaemia & 0.01 & 27.92 & 2.04 & 380.96 \\
\hline
\end{tabular}

OR 0.15 , CI $0.04-0.51$ ) associated with low risk of CP for the female which means that, male children were at higher risk of developing cerebral palsy. Having only 1 pregnancy before (primigravida) was another independent variable which showed significance and low risk for $\mathrm{CP}$ ( $\mathrm{P}$ value $\leq 0.05$, OR 0.24, CI $0.10-0.60$ ). Three variables showed high significance as a risk factor for $\mathrm{CP}$. and hypocalcaemia all showed significant results, Asphyxia (P value of 0.00 OR $10.58,95 \%$ CI 3.59 - 31.2), hypoglycemia (P value 0.00, OR 40.99, 95\% CI 6.93 242.270) and hypocalcaemia (P value 0.01, OR 27.92, 95\% CI 2.04 - 380.96).

\section{DISCUSSION}

Although we do not have actual numbers about the incidence or prevalence of cerebral palsy among Iraqi children, we can still rely on reports of the medical doctors in charges of those cases, who have been regularly reporting an unprecedented numbers of children diagnosed with cerebral palsy annually. In response to those reports, we decided it is the time to highlight the problem. The tunnel looked very dark at the beginning as causes of cerebral palsy are variable and multiple including, genetic, prenatal, and perinatal and postnatal factors. Moreover, no single study or person has ever claimed finding the real and definite cause of cerebral palsy. This fact comes from the complicity and overlapping of the causes of cerebral palsy with each other's. The importance of studying cerebral palsy comes from the fact that, this disorder can impose a huge burden on the family psychologically, emotionally, financially and socially. Moreover, it could also constitute a major burden on the national health system because it is simply a chronic disorder, and it needs collaborative efforts and team work between many parties and organizations for treatment and rehabilitation. And most importantly it can cost lots of money which, many health experts and planners would argue that, this large amounts of money would be better (in terms of cost effectiveness and cost benefit) if spent on more broad and basic health care programmes, like primary care and preventive medicine. On the other hand, if a cerebral palsy child is left without proper diagnoses, treatment and rehabilitation; this could even have a worse consequences on the family, the society and the welfare heath system in any country around the world.

A very significant finding from our study was, an independent 8 folds increased risk for developing cerebral palsy among children whose mothers were employed compared to those whose mothers were unemployed. In other words, children whose mothers were employed had almost 8 times higher risk of developing cerebral palsy than those children whose mothers were unemployed. In our study we investigated the average income of the family as well but the results were insignificant. Regarding the employment status variable in our study, the variable we studied was if the mother was employed or not. In most studies the researchers were looking for the socioeconomic status of the parents of cerebral palsy child rather than the employment status. Like in one particular study where, they have come up with a result showing a linear association between risk of $\mathrm{CP}$ and socioeconomic status [17].

Our study did not actually show similar trends for this socioeconomic variable as the results of our study indicated that employment of the mother was a risk factor to develop cerebral palsy. Probably the stress that the mother could get from the work load pressure would have a higher adverse effect on her pregnancy compared to the advantage that she can get from the better income from her employment, and this in turn may eventually result in having a baby with $\mathrm{CP}$.

One independent variable that was significantly showing low risk association with development of cerebral palsy in our study was the female gender of the child. In other words, male children were at higher risk of developing cerebral palsy. Although, not many studies have shown this association of the gender of children with cerebral palsy, this association was mentioned clearly in one Swedish study where, male gender was repeatedly found to constitute a risk factor for cerebral palsy [16].

Primigravida was another independent maternal variable which showed a significant low risk association with $\mathrm{CP}$ (P value 0.00, OR 0.24, CI 0.10 - 0.60). Our finding did not agree with the finding of one previous study where, they have found that primigravid (having one pregnancy before) was associated with development of cerebral palsy among children (OR 5.52) [12].

One of the perinatal variables that showed significance in our study was, asphyxia of the neonate which was found to be independently associated with 10 times higher risk of developing cerebral palsy. Asphyxia had been known for a long time as a risk factor for cerebral palsy, until some recent studies started to show a differ- 
ent trend. Perinatal asphyxia was mentioned as a risk factor of developing cerebral palsy in 2 studies conducted in Turkey which is a border country to Iraq. $[9,18]$ This might coincidently highlight the fact that, some risk factors for different diseases and disorders may follow a regional international trend in addition to the similarities within the same country. The last 2 independently significant variables in our study were hypoglycemia and hypocalcaemia which both showed very strong association with cerebral palsy ( $\mathrm{OR}=38,16$ respectively). Hypoglycemia and hypocalcaemia were mentioned as potential risk factors for developing cerebral palsy in very old pediatric and child health books. We could not even find any study with a positive association between those 2 variables and cerebral palsy in literature. Realistically, the hospital services situation in Iraq during and after 2003 war might very well go with the finding of our study regarding hypoglycemia and hypocalcaemia as, simple basic neonatal care procedures were a challenging task at that time.

\section{CONCLUSIONS \& RECOMMENDATION}

Our study came to a conclusion that neonatal care services in Iraq should be reviewed and it should get more attention and support from the governmental and not governmental institutions as neonatal asphyxia, hypoglycemia and hypocalcaemia still constituted the major risk factors for cerebral palsy in Iraq. Basically, and due to the consecutive wars the country faced in the 80 's, 90 's and in 2003, the antenatal and neonatal care programmes suffered many shortages in terms of technology and organization. If we want to help solving the problem of cerebral palsy in Iraq, we should allocate more resources to develop a better antenatal and neonatal care services as the causes of cerebral palsy in Iraq was still the result of deficit in those 2 important factors. In addition, we can use the results of this study to strengthen the need for more health promotion programmes for a better antenatal care and better hospital obstetric and neonatal services. Furthermore, we could encourage the national and international nongovernmental organizations to offer more support in this regard, and also encouraging the private sector to invest more in neonatal care services in Iraq. Last but not least, this study was a case-control study, which was conducted based on retrospective events. If we can do a cohort study in the future with similar objectives, we would definitely have more accurate results especially in terms of temporal relationship between the outcome and the risk factors.

The Strength of our study comes from the fact that all the cerebral palsy cases were diagnosed professionally by either a pediatrician or neurologist or both. The sample represented many populations as cases of $\mathrm{CP}$ referred from different parts of Iraq to this very specific children hospital in the center of Baghdad, the capital of Iraq. The sample represented all sectors of Iraqi population as all ethnic groups were represented, and this gives us more freedom to generalize our findings.

Interviewer or questionnaire administers was one bias as the researcher was individually interviewing and selfadministering the questionnaire. Another limitation that faced us during the study was the availability and reliability of individual patient medical cards and the hospital medical records (Expiry for data records is 5 years in certain hospitals in Iraq). Last but not least, exploring the maternal and foetal risk factors as part of the prenatal and perinatal period of the child's delivery without exploring the postnatal factors does leave a gap, however, we tried to close this gap by excluding any child with history of one or more of postnatal risk factors of $\mathrm{CP}$ to emphasize on the antenatal and perinatal factors.

\section{REFERENCES}

[1] Crooker, L.C. (1994) Developmental-behavioral pediatrics. Cerebral Palsy, 95, 579-588.

[2] Wolraich, M., Droter, D., Dworkin, P. and Perrin, E. (2008) Developmental-behavioral pediatrics. Evidence and Practice, 14, 483-517.

[3] Glew, G.M. and Bennett, F.C. (2011) Cerebral palsy grown up. Journal Developmental \& Behavioral Pediatrics, 32, 469-475. doi:10.1097/DBP.0b013e3182202d42

[4] Gilbert, W.M., Jacoby, B.N., Xing, G., Danielsen, B. and Smith, L.H. (2010) Adverse obstetric events are associated with significant risk of cerebral palsy. American Journal of Obstetrics \& Gynecology, 203, 328. doi:10.1016/j.ajog.2010.05.013

[5] Leviton, A. (1993) Preterm birth and cerebral palsy, is tumor necrosis factor the missing link? Developmental Medicine \& Child Neurology, 35, 1101-1106.

[6] Wu, Y.W. and Colford, J.M. Jr. (2000) Chorioamnionitis as a risk factor for cerebral palsy, a meta-analysis. Journal of the American Medical Association 284, 1417-1426. doi:10.1001/jama.284.11.1417

[7] Shatrov, J.G., Birch, S.C., Lam, L.T., Quinlivan, J.A., McIntyre, S. and Mendz, G.L. (2010) Chorioamnionitis and cerebral palsy. A meta-analysis. Obstetrics \& Gynecology, 116, 387-392.

doi:10.1097/AOG.0b013e3181e90046

[8] Keough, J.M. and Badawi, N. (2006) The origins of cerebral palsy. Current Opinion in Neurology, 19, 129-134. doi:10.1097/01.wco.0000218227.35560.0d

[9] Ozturk. A., Dimerci, F., Yavuz, T., Yildiz, S., Degirmenci, Y., Dosoglu, M. and Avsar, Y. (2006) Antenatal and delivery risk factors and prevalence of cerebral palsy in Duzce (Turkey). Brain and Development, 29, 39-42. doi:10.1016/j.braindev.2006.05.011

[10] Petterson, B., Nelson, K.B., Watson, L., et al. (1993) Twins, triplets, and cerebral palsy in births in Western 
Australia in the 1980s. British Medical Journal, 307, 1239-1243. doi:10.1136/bmj.307.6914.1239

[11] Bonellie, S.R., Currie, D. and Chalmers, J. (2005) Comparison of risk factors for cerebral palsy in twins and singletons. Developmental Medicine \& Child Neurology, 47, 587-591.

[12] Costantine, M.M., How, H.Y., Coppage, K., Maxwell, R.A. and Sibai, B.M. (2007) Does peripartum infection increase the incidence of cerebral palsy in extremely low birth weight infants? American Journal of Obestetrics \& Gynecology, 196, e6-e8.

[13] Hall, D. (1989) Birth asphyxia and cerebral palsy. British Medical Journal, 29, 279-282. doi:10.1136/bmj.299.6694.279

[14] Pless, I.B. (1994) The epidemiology of childhood disorders, cerebral palsy. Guilford Press, New York.

[15] Thorngren-Jerneck, K. and Herbst, A. (2006) Perinatal factors associated with cerebral palsy in children born in Sweden. Obstetrics \& Gynecology, 108, 1499-1505. doi:10.1097/01.AOG.0000247174.27979.6b

[16] Hagberg, B., Hagberg, G., Beckung, E., et al. (2001) Changing panorama of cerebral palsy in Sweden. VIII. Prevalence and origin in the birth year period 1991-94. Acta Paediatrica, 90, 271-277. doi: $10.1080 / 080352501300067532$

[17] Sundrum, R., Logan, S., Wallace, A. and Spencer, N. (2005) Cerebral palsy and socioeconomic status, a retrospective cohort study. Archives of Diseases in Childhood, 90, 15-18.

[18] Erkin, G., Delialioglu, S.U., Ozel, S., Culha, C. and Sirzai, H. (2007) Risk factors and clinical profiles in Turkish children with cerebral palsy, analyses of 625 cases. International Journal of Rehabilitation Research, 31, 107170. 